\title{
Stochastic landslide vulnerability modeling in space and time in a part of the northern Himalayas, India
}

\author{
Iswar Das • Gaurav Kumar • Alfred Stein • \\ Arunabha Bagchi • Vinay K. Dadhwal
}

Received: 4 January 2010 / Accepted: 12 August 2010 / Published online: 1 September 2010

(C) The Author(s) 2010. This article is published with open access at Springerlink.com

\begin{abstract}
Little is known about the quantitative vulnerability analysis to landslides as not many attempts have been made to assess it comprehensively. This study assesses the spatio-temporal vulnerability of elements at risk to landslides in a stochastic framework. The study includes buildings, persons inside buildings, and traffic as elements at risk to landslides. Building vulnerability is the expected damage and depends on the position of a building with respect to the landslide hazard at a given time. Population and vehicle vulnerability are the expected death toll in a building and vehicle damage in space and time respectively. The study was carried out in a road
\end{abstract}

I. Das · A. Stein

Department of Earth Observation Science (EOS),

Faculty of Geo-Information Science and Earth

Observation (ITC), University of Twenty,

P.O. Box 217, 7500 AE, Enschede, The Netherlands

I. Das · G. Kumar · V. K. Dadhwal

Indian Institute of Remote Sensing, 4-Kalidas Road,

Dehradun, India

I. Das $(\varangle)$

Department of EOS, ITC, P.O. Box 217, 7500 AE,

Enschede, The Netherlands

e-mail: das@itc.nl

A. Bagchi

University of Twenty, $7500 \mathrm{AE}$,

Enschede, The Netherlands corridor in the Indian Himalayas that is highly susceptible to landslides. Results showed that $26 \%$ of the buildings fall in the high and very high vulnerability categories. Population vulnerability inside buildings showed a value $>0.75$ during 0800 to 1000 hours and 1600 to 1800 hours in more buildings that other times of the day. It was also observed in the study region that the vulnerability of vehicle is above 0.6 in half of the road stretches during 0800 hours to 1000 hours and 1600 to 1800 hours due to high traffic density on the road section. From this study, we conclude that the vulnerability of an element at risk to landslide is a space and time event, and can be quantified using stochastic modeling. Therefore, the stochastic vulnerability modeling forms the basis for a quantitative landslide risk analysis and assessment.

Keywords Landslide • Stochastic vulnerability • Elements at risk $\cdot$ India

\section{Introduction}

Landslides are a common and important natural hazard in mountainous areas throughout the world. The international emergency disaster database showed that there are 35 landslides events in 2008, killing 3,924 people and affecting some 3.8 million people directly in different parts of the 
world. Estimated damage from these events is up to 4.5 million US Dollars (EM-DAT 2008). Landslides frequently occur in the Indian Himalayas where, for example, a landslide in Ukhimath on 11 August 1998 affected an area of $20 \mathrm{~km}^{2}$, taking the lives of 102 people (Naithani et al. 2002), heavy rainfall triggered more than 200 landslides in the Byung area of Rudraprayag district of Uttarakhand on 16 July 2001, killing 27 people (Vinod Kumar et al. 2003), and the Varunavat landslide in Uttarkashi in September 2003 damaged million dollars worth of properties though no human casualty (Vinod Kumar et al. 2008).

With the growing population and industrial developments in hilly regions of the world, the threat of landslide disaster has increased. Vulnerability to landslides in hilly terrains, however, is little known or discussed (Galli and Guzzetti 2007). Varnes (1984) defines vulnerability to landslides as, "the degree of loss to a given element-or set of elements-at risk resulting from the occurrence of a given magnitude of landslide in an area". Assessing vulnerability of an area has thus become a basis for information to recognize measure and predict risk for mitigation and prevention of an expected disaster. Vulnerability assessment of landslides however is complex, the reason being that landslides occur at comparatively isolated locations leading to damages at local scales (Van Westen et al. 2006). Modeling of landslide vulnerability is also complex as the spatial and temporal uncertainty of landslides coupled with the dynamic nature of different types of elements at the risk generates complex scenarios (van Westen et al. 2008). In fact, movement of people and vehicles on roads is difficult to track, as it shows changes at the daily, weekly, and monthly scales (Roberds 2005).

Landslides may occur at unexpected locations at an unknown moment in time, and hence are considered to be a stochastic process. The sequence of outcomes of stochastic processes can often be modeled using probability based approaches. Such a stochastic process can be defined as a phenomenon unfolding itself in time according to a probability law and stochastic theory may help to better understand them. Mathematically, stochastic processes $X(t, s)$ can be defined as a non-countable infinity of random variables, one for each time $(t)$ and location (s). It is defined in terms of the probability distribution $F_{t, s}(x)$, (Papoulis 1991):

$$
F_{t, s}(x)=P\{X(t, s) \leq x\}
$$

The concept of a stochastic process was first applied in the field of biostatistics and it has found a general use in risk assessment and environmental sciences (Elbers and Gunning 2003). In landslide studies, vulnerability of elements at risk to a landslide is considered stochastic because of the randomness of the landslide events. This is because, vulnerability of an element at risk to a landslide changes over time and the effect of the landslide is sensitive to the choice of time horizon (Elbers and Gunning 2003). Research in the past (Glade 2003; Roberds 2005; Kohle et al. 2007) has shown that an important cause of randomness in vulnerability is the dynamic behavior of the various exposed elements at risk.

Dai et al. (2002) from a landslide perspective showed that vulnerability assessment is somewhat subjective and mainly depends on the historical records like run-out distance, volume, velocity of sliding, and the nature and type of elements at risk and their proximity to a slide. In studies in China, empirical models have mainly been used for the assessment of vulnerability, risk, and hazard of debris flow prone areas (Liu et al. 2002; Liu and Lei 2003; Liu 2006). So far, there is no unique and simple method available for the assessment of vulnerability within a landslide risk analysis framework (Glade 2003). This is mainly due to the complex nature of temporal variability of the elements at risk (Roberds 2005; Duzgun and Lacasse 2005). Landslide vulnerability assessment is complicated because of the complexity in spatio-temporal modeling (Van Westen et al. 2006; Birkmann 2007). In fact, vulnerability is dynamic in nature and hence should be assessed by taking both spatial and temporal aspect into consideration (Fuchs and Hubl 2007; Galli and Guzzetti 2007). Kaynia et al. (2008) proposed a probabilistic estimation of landslide vulnerability that has been applied to estimate the susceptibility to structure and susceptibility of person in structure. In this study "first order second 
moment" approach has been proposed to assess the vulnerability.

Probabilistic methods have become popular in landslide studies particularly with increasing sophistication of geographic information systems, allowing integration of data collected from various sources and methods and at different scales. Remote-sensing-based mapping and data collection has been an additional step forward, in particular for areas that are difficult to access. As a result, remotely sensed data has been widely used to extract various elements at risk (Ebert et al. 2009; Shamaoma 2005).

The aim of this study is to develop and apply a methodology to assess the vulnerability of landslides in space and time in a region of the northern Himalaya. It assesses the vulnerability in a stochastic way and models the dynamics of different vulnerable elements. The methodology is applied to a hazard prone study area using different scenarios of day and night-time vulnerability leading to the optimal assessment of landslide vulnerability.

\section{Methods}

A probabilistic approach to landslide vulnerability

The United Nations, D. o. H. A. (1992) defined vulnerability as "the degree of possible loss (from $0 \%$ to $100 \%$ ) resulted from potentially damaging phenomena". Vulnerability assessment studies in contemporary natural sciences are far ahead in comparison to the landslide field. Limited studies have been carried out on the vulnerability to landslides, despite landslides causing frequent and widespread damage to the population and the infrastructures in many areas of the world (Galli and Guzzetti 2007). This may be because landslides are spatially discrete phenomena unlike earthquakes, floods, and hurricanes, which have spatially continuous loss measurement parameters such as ground motion, rainfall, and wind speed, respectively (Duzgun and Lacasse 2005). Therefore, quantifying vulnerability to landslide is a challenge. We define vulnerability as a stochastic consequence of a landslide that quantifies the potential loss in space and time, and hence is expressed as a probability. We consider a set of objects $O=\{b(i), p(j), v(k), i=$ $1, \ldots, I, j=1, \ldots, J, k=1, \ldots, K\}$ that are vulnerable to landslide, where $b(i)$ is the $i$ th building, $p(j)$ is the $j$ th person and $v(k)$ is the $k$ th vehicle at risk. The vulnerability of $i$ th building, $V_{b(i)}$, depends on the location $s$ with respect to the landslide. We will distinguish the spatial vulnerability of the buildings, denoted as $V_{b(i)}(s)$, from the vulnerability $V_{b(i) p(j)}(s, t)$ of the persons $p(j)$ inside the buildings $b(i)$ that varies in space and time. Similarly, the vulnerability of vehicle $V_{v(k)}(s, t)$ depends on the position $s$ and the time $t$ on the road and the vehicle density. The probabilistic approach in this study is based upon three spatio-temporal elements at risk, respectively:

- The building as a static spatial element at risk $E_{b(i)}(s)$, expressed as the maximum unit cost of the building

- The population as dynamic element at risk in space and time $E_{b(i) p(j)}(s, t)$, expressed as number of persons within a building

- Vehicles on the road as dynamic element at risk in space and time, $E_{v(k)}(s, t)$, expressed as the expected number of vehicles

The probability that a building will be hit by landslide will depend on the location of the building with respect to landslide. As the building position is fixed with respect to a landslide event, a logistic regression method has been adopted for calculating the relationship of building with landslides. A logistic regression model describes the relationship between a dichotomous response variable $Y$, here landslide 'presence' or 'absence', and the explanatory variable as the buildings. Since $Y$ is a dichotomous variable, it has a Bernoulli distribution with parameter $p=\operatorname{Pr}(Y=1)$, that is, $p$ is the probability of occurrence of an event for given values $i=1,2, \ldots \ldots \ldots, I$ of the explanatory variables (Hosmer and Lemeshow 2000).

In a logistic regression the expected value of $Y$ equals:

$$
E(Y)=\frac{1}{1+\exp \left[-\left(\beta_{0}+\beta_{1} b_{i}\right)\right]}
$$

where $\beta_{0}$ is a constant and the $\beta_{1}$ is the coefficient of the predictor variable $b$ the building. 
In landslide vulnerability mapping of the buildings a logistic regression model incorporates the occurrence of landslides as a discrete and dichotomous response variable, and the locations of the buildings as explanatory variables to generate a conceptually rational function Eq. 2.

For the dynamic elements like the population inside buildings and the vehicles on the road, however, a random-point events method like the Poisson model has been adopted. The Poisson model is a continuous-time model consisting of random-point events that occur independently in ordinary time, which is considered naturally continuous. For landslide vulnerability study the Poisson model is used for calculation of spatiotemporal probability of population and vehicles in a particular area with respect to landslide occurrence. This is because the dynamic elements like population and vehicles are space-time phenomena. The assumptions made include: (1) the numbers of events (landslides) which occur in disjoint time intervals are independent. (2) The probability of an event occurring in a very short time interval is proportional to the length of the time interval. (3) The probability of more than one event in such a short time interval is negligible. (4) The probability distribution of the number of events remains the same for all time intervals of a fixed length.

The vulnerability of population inside buildings, i.e., people being hit by a landslide, largely depends on the temporal spatial probability of the people inside the buildings at the time of occurrence of the landslide. The probability of people being hit in a time $t$ is given by

$$
\begin{aligned}
& P=[N(t)=N]=\exp (-\lambda(p) t) *\left[(\lambda(p) t)^{n} / n !\right] \\
& n=0,1,2,3 \ldots \ldots
\end{aligned}
$$

\section{Where}

$N$ is the total number of population present during a specified time period $t$

$\lambda(p)$ : average population living inside the buildings

The vulnerability to a moving vehicle, i.e., vehicle being hit by a landslide, largely depends on the temporal spatial probability of the vehicle at the time of occurrence of the landslide. The probability of vehicle being hit in a time $t$ is given by

$$
\begin{aligned}
& P=[N(t)=N]=\exp (-\lambda(v) t) *\left[(\lambda(v) t)^{n} / n !\right] \\
& n=0,1,2,3 \ldots \ldots
\end{aligned}
$$

\section{Where}

$N$ : is the total number of vehicle present during a specified time period $t$

$\lambda(v)$ : average vehicle density on the road

The expected number of vehicles on the road and the population movement inside the buildings at different times of the day were estimated by assuming that similar conditions apply throughout the year. We also assumed that all elements at risk present within the study area are equally vulnerable to landslide. Criteria to assess the vulnerability were the monetary values for property loss, the average population density for population damage, and the maximum number of expected vehicles on any moment of time on part of road track, respectively. On the basis of these criteria, threshold values for maximum damage were selected for each element at risk. The threshold value for elements at risk was transformed into a probability by using the sigmoid curve equation for property value and the Poisson curve equation for population density. With the help of these transformed values, vulnerability of all observed elements at risk was generated for different time zones.

\section{Vulnerability assessment}

The logistic regression model applied to landslide vulnerability of the buildings can be modeled as

$\operatorname{Pr}\left[V_{b(i)}(s)\right]=1 /\left(1+\exp \left(\alpha_{1}\left(E_{b(i)}(s)\right)+\alpha_{0}\right)\right.$

where the coefficients $\alpha_{0}$ and $\alpha_{1}$ are the intercept and coefficient of a Logit function and are obtained from the analysis of damage data collected from the study area. Equation 5 represents a sigmoid curve and assumes that the property accumulation fits a Logit curve. Historical records of damage information of roads and buildings were assessed while generating the vulnerability conditions. $V_{b(i)}(s)$ values were assessed on the 
basis of expected loss considering the maximum building cost for a complete damage condition.

To assess vulnerability for persons at different times of the day, we used a 2-h time resolution that is refined to a $1 \mathrm{~h}$ resolution between 0800 and 1000 and between 1600 and 1800 hours when population dynamics usually is higher. For the calculation of population vulnerability, the maximum number of persons occupying a building is considered as a Poisson equation.

$\operatorname{Pr}\left[V_{b(i) p(j)}(s, t)\right]=1-\exp \left(\gamma E_{b(i) p(j)}(s, t)\right)$

where the coefficient $\gamma$ is obtained from the damage data in the study area. $V_{b(i) p(j)}(s, t)$ values were quantified using a maximum threshold of 70 people on the basis of local information. The Poisson curve model as in Eq. 6 was applied to calculate the vulnerability values at different times of the day.

Vulnerability of a vehicle on the road depends on its relative position with respect to a hazard at a specific time. To assess the expected number of cars on a $1-\mathrm{km}$ road section on an hourly basis, we took a constant average vehicle speed equal to $35 \mathrm{~km} / \mathrm{h}$. We calculated the expected number of vehicles at any given time on the part of road section as suggested by Guzzetti (2005)

$N_{V}=\frac{\text { Average daily traffic }}{\text { Average speed of vehicle }} \times$ Travel time

where,

$N_{V}=$ is the expected number of vehicles at any time on road section

Travel time $=$ time taken by vehicles to travel unit distance on road

The vulnerability of vehicle on the road is assessed by considering each of the road section and the time scale that was used for population vulnerability calculation. In order to assess vehicle vulnerability similar concept as applied to assess the population vulnerability was adopted with coefficients derived from the damage data.

$\operatorname{Pr}\left[V_{v(k)}(s, t)\right]=1-\exp \left(\delta \cdot E_{v(k)}(s, t)\right)$

where the coefficient $\delta$ is obtained from the damage data in the study area. To assess the vulnerability of vehicle on a road section, the expected number of vehicle at any given time interval was calculated using (8).
Fig. 1 The distribution of intercept (a) and coefficient (b) values obtained from a logistic regression model using Eq. 5 for building vulnerability and the convergence of two chains for these values (c and d) using Monte Carlo simulation
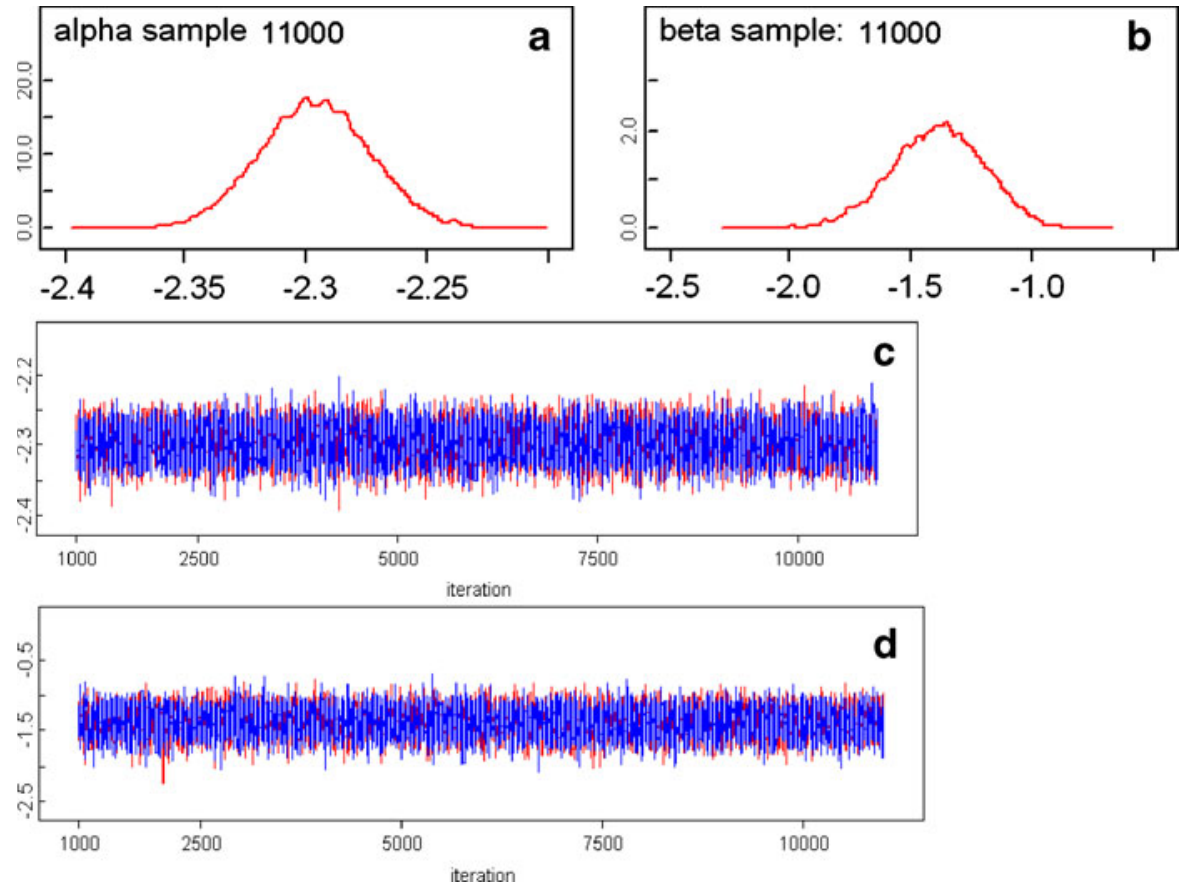
The coefficients for buildings, population, and vehicles were generated through a Bayesian analysis approach adopted using WinBUGS program 3.0.3 (Copyright (C) 1989, 1991 Free Software Foundation, Inc. 59 Temple Place-Suite 330, Boston, MA 02111-1307, USA). The data were first converted into ASCII format for inputting into the WinBUGS program. Using GLM function, Eq. 5 was obtained and by regression, the exponential function Eqs. 6 and 8 were obtained. The intercept and coefficient for Eq. 5 was found to be 1.392 and 2.296, respectively. The pdfs and history of trace plots obtained are shown in Fig. 1. Similarly, the coefficients obtained using the Eqs. 6 and 8 were 0.025 and 0.429 , respectively.

\section{Site characteristics and data collection}

The study area is located in the northern Himalayas, India, in the catchment of the river Bhagirathi, a tributary of the river Ganges (Fig. 2). It lays between $30^{\circ} 47^{\prime} 29^{\prime \prime} \mathrm{N}$ and $30^{\circ} 54^{\prime} 45^{\prime \prime} \mathrm{N}$ latitude and $78^{\circ} 37^{\prime} 41^{\prime \prime} \mathrm{E}$ and $78^{\circ} 44^{\prime} 03^{\prime \prime} \mathrm{E}$ longitude. The area is transacted by a national highway corridor connecting Uttarkashi and Gangotri, being the lifeline for the people living in the interior (Agarwal and Kumar 1973). Elevation in the area ranges between 1,572 and $2,009 \mathrm{~m}$. The catchment receives heavy precipitation during the summer monsoon between July and September and moderate rainfall during the winter monsoon from January to March. On average there are 100 rainy days in a year and average annual rainfall is 1,200 mm (Das et al. 2008; Vinod Kumar et al. 2008). In the Himalayan region, landslides are recurring annually and are prominent during the summer monsoon. The frequent occurrence of landslides is a major threat for the economy in the area (NRSA 2001). Landslides in this area are the result of a combination of an intrinsic geology, adverse natural topography like steep slopes, weathered rocks and soils, human influences on the topography, and high rainfall (Saha et al. 2005; Choubey and Ramola 1997). The landslides considered in this study are mainly shallow translational rock slides that are prominent in this area. The national highway gets blocked by landslides on average once per week during the summer monsoon.

Field data were collected at different temporal resolutions. Base data of buildings and road were
Fig. 2 Location and extent of the study area depicted on Cartosat-1 satellite image showing the road and the buildings

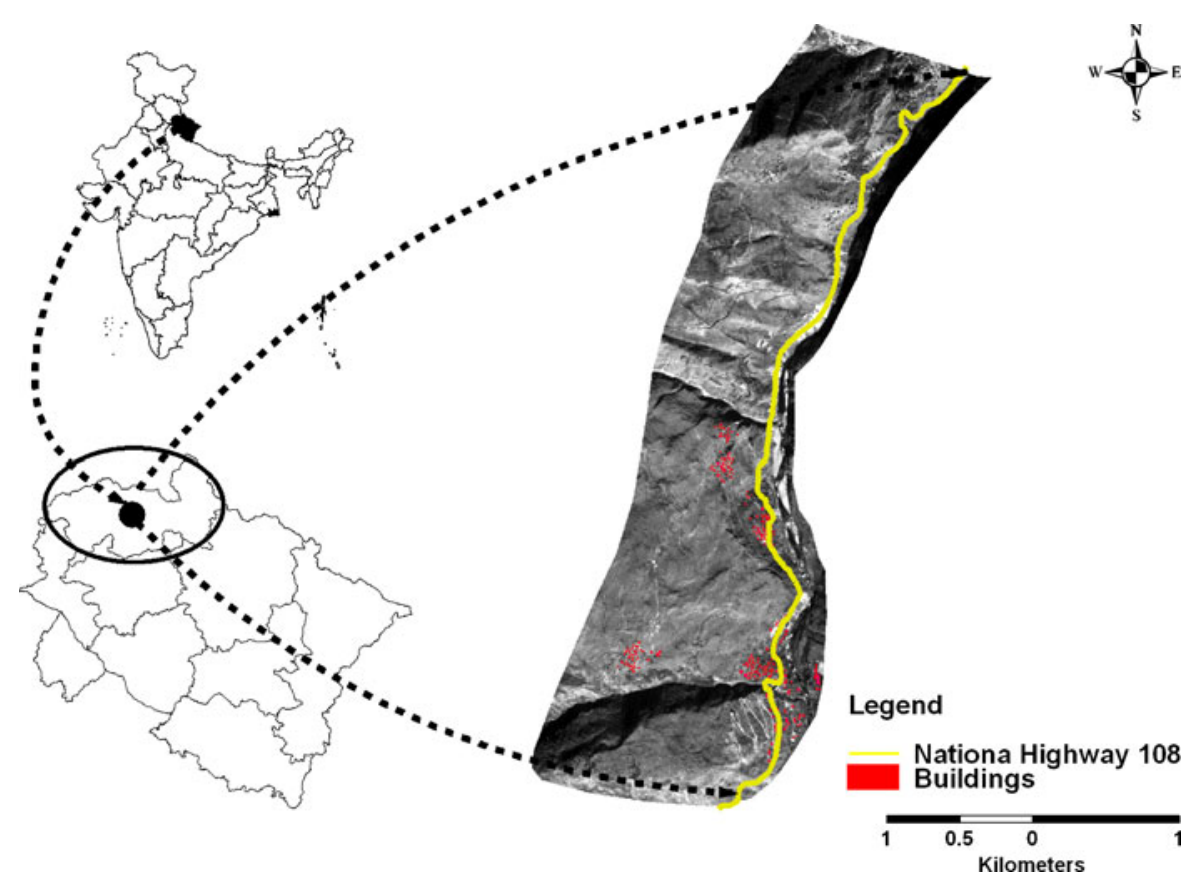




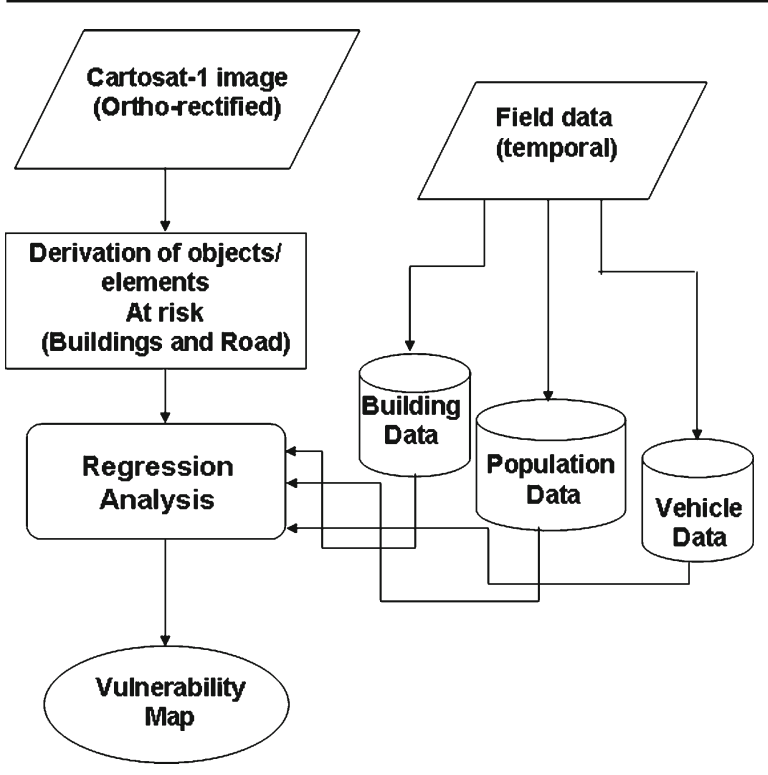

Fig. 3 A generalized methodology flow chart showing the type of data collection and analysis

extracted by visual interpretation from a $2.5 \mathrm{~m}$ resolution Cartosat-1 image, yielding 281 buildings such as residential houses, business establishments, schools, government offices, a hospital and a guest house, and a 7-km national highway road segment. Archived landslide data from 1982 to 2009 were used to generate a damage database. Field surveys were carried out to investigate the pattern of population movement and to assess the vehicle density on the road segment at different times of the day. Two types of data were collected: primary data based on personal interviews with the local population and secondary data obtained from government offices. On the basis of these data vulnerability conditions were developed (Fig. 3).
Primary data

Primary data were collected based on the set of questionnaire answered by the locals. The identified 281 buildings were surveyed and their GPS locations were stored. Several types of questionnaires were set and interviews were conducted with persons related to the buildings (Table 1). This provided information about the occupancy of the different types of buildings at different times of the day. Vehicle frequency at different road sections was measured by hourly monitoring of the vehicle movement. For each vehicle the passenger capacity was taken on the basis of number of seats in that vehicle (Table 2).

\section{Secondary data}

Secondary information was collected from different government departments. The census data of the study area were obtained from the Block office and from the Junior Secondary School, Bhatwari. Construction costs for each kilometer of the road were collected from the road construction departments in India. It was assumed that the mean construction cost for each building is the same; as maximum buildings in the area mostly have one storey and construction material for each building is similar. A $40 \$$ mean construction cost per square meter was considered as the upper limit. Average construction costs of building per square foot in the region were obtained from the district civil construction department in the study area. To get the value of buildings in each cell, the actual coverage of buildings in a cell, being partial or full depending on their location was multiplied with the mean

Table 1 Information collected about population accumulation in different places at different time of the day from the field survey

\begin{tabular}{|c|c|c|c|c|c|c|c|c|c|c|c|}
\hline \multirow[t]{3}{*}{ Sl no. } & \multirow[t]{3}{*}{ Building type } & \multicolumn{10}{|c|}{ Population present in each type of building during different time of the day } \\
\hline & & 0600 to & 0800 to & 0900 to & 1000 to & 1200 to & 1400 to & 1600 to & 1700 to & 1800 to & 2000 to \\
\hline & & 0800 & 0900 & 1000 & 1200 & 1400 & 1600 & 1700 & 1800 & 2000 & 0600 \\
\hline$\overline{1}$ & Residential house & 4 & 2 & 1 & 1 & 1 & 1 & 2 & 3 & 3 & 4 \\
\hline 2 & Office & 1 & 1 & 19 & 19 & 19 & 19 & 19 & 1 & 1 & 1 \\
\hline 3 & School & 0 & 0 & 56 & 56 & 56 & 56 & 0 & 0 & 0 & 0 \\
\hline 4 & Shop & 5 & 5 & 5 & 5 & 5 & 5 & 5 & 5 & 5 & 0 \\
\hline 5 & Guest house & 25 & 18 & 5 & 5 & 5 & 5 & 15 & 21 & 21 & 25 \\
\hline
\end{tabular}


Table 2 Vehicle movement on different examined road section during the field survey

\begin{tabular}{|c|c|c|c|c|c|c|c|c|c|c|c|}
\hline \multirow[t]{3}{*}{ Sl no. } & \multirow[t]{3}{*}{ Road sections } & \multicolumn{10}{|c|}{ Vehicles moving on the road during different time of the day } \\
\hline & & 0600 to & 0800 to & 0900 to & 1000 to & 1200 to & 1400 to & 1600 to & 1700 to & 1800 to & 2000 to \\
\hline & & 0800 & 0900 & 1000 & 1200 & 1400 & 1600 & 1700 & 1800 & 2000 & 0600 \\
\hline 1 & Section 1 & 58 & 119 & 123 & 137 & 124 & 137 & 128 & 119 & 113 & 0 \\
\hline 2 & Section 2 & 67 & 117 & 128 & 141 & 131 & 137 & 135 & 124 & 119 & 0 \\
\hline 3 & Section 3 & 72 & 114 & 124 & 138 & 128 & 135 & 132 & 121 & 116 & 0 \\
\hline 4 & Section 4 & 68 & 111 & 123 & 133 & 124 & 127 & 128 & 121 & 111 & 0 \\
\hline 5 & Section 5 & 59 & 97 & 103 & 116 & 102 & 109 & 95 & 104 & 84 & 0 \\
\hline 6 & Section 6 & 56 & 91 & 96 & 109 & 102 & 111 & 89 & 97 & 81 & 0 \\
\hline 7 & Section 7 & 59 & 94 & 93 & 111 & 107 & 114 & 92 & 102 & 83 & 0 \\
\hline
\end{tabular}

construction cost of the buildings. Total vehicle frequency per day and average allowed speed for vehicle were collected from the traffic control department of the district town in the area.

\section{Results}

Magnitude loss relationship was established by means of an analysis of landslide volume and the corresponding road length damaged. Taking the highest length of road damage as 1.0, a scatter plot was generated between the proportion of road length damaged and the volume of landslide material for 150 recorded landslides (Fig. 4). Having thus determined the frequency of large and small damaging events, we noticed that $80 \%$ of the landslides are small, e.g., causing a road damage of a proportion below 0.2. This agrees with a power law distribution of the landslide volume and the related probability density function

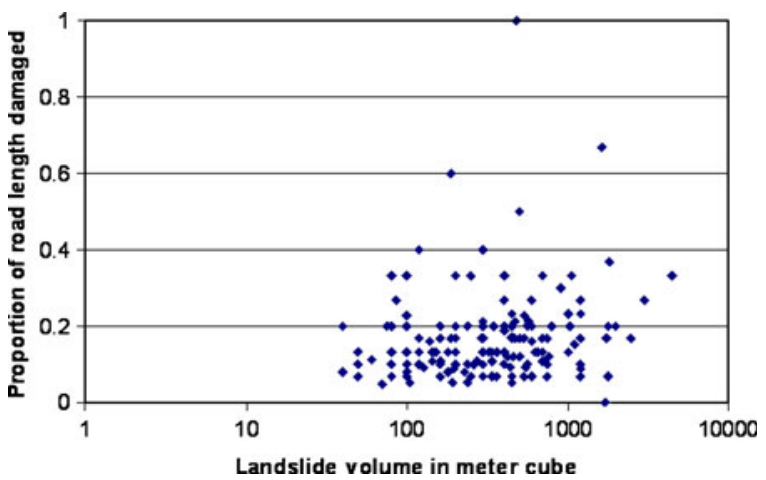

Fig. 4 Relationship between estimated landslide volume and the proportion of road damaged for 150 landslides that larger events are rare (Fig. 5). To calculate the vulnerability, the study area was divided into $100 \times 100-\mathrm{m}$ cell size using the assumption that a single landslide event does not exceed an area larger than $0.01 \mathrm{~km}^{2}$.

\section{Vulnerability assessment of buildings}

The majority of grids $(51 \%)$ containing buildings showed low vulnerability ( 0.0 to 0.25$)$. Moderate $(0.25-0.5)$, high $(0.5-0.75)$, and very high (0.75-1.0) vulnerability categories corresponded to $23 \%, 12 \%$, and $14 \%$ of the grid cells, respectively. Obtained $\operatorname{Pr}\left[V_{b(i)}(s)\right]$ values were then

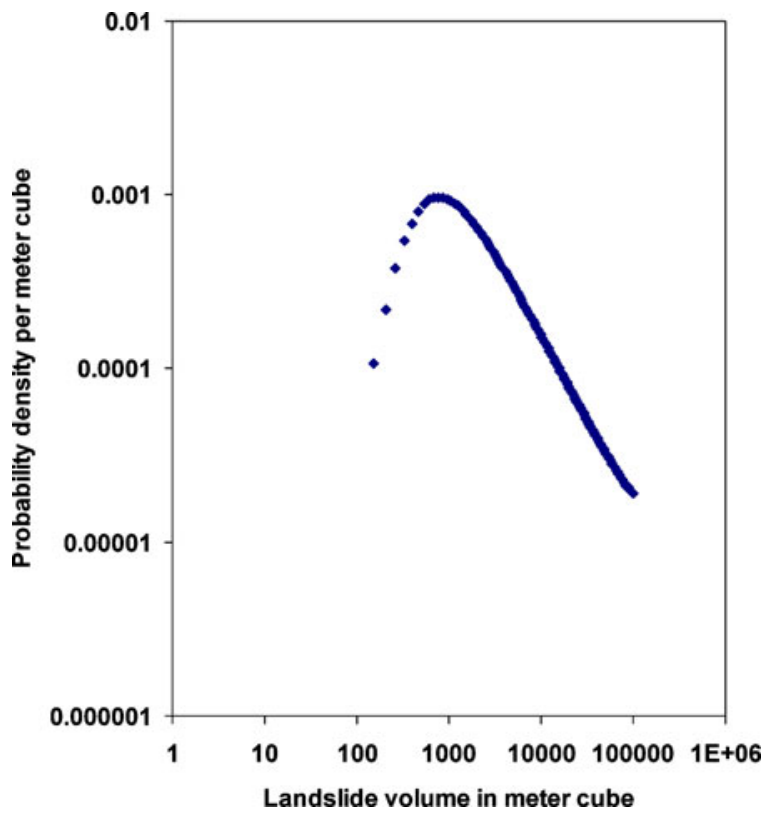

Fig. 5 Dependence of landslide probability density on landslide volume 


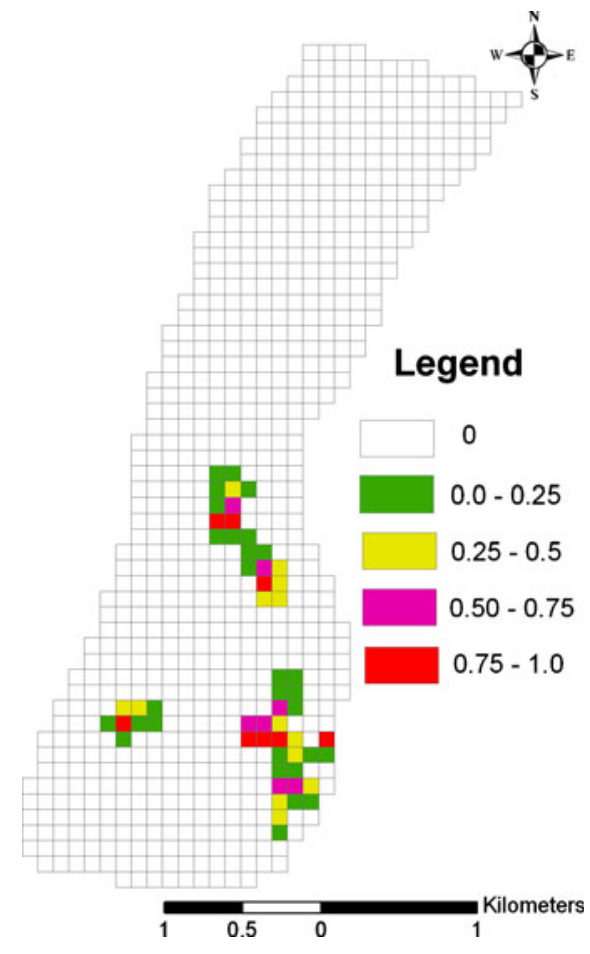

Fig. 6 Building vulnerability map showing the vulnerability condition of buildings at different locations in the study region

used to generate the building vulnerability map (Fig. 6).

Vulnerability assessment of population in buildings

Vulnerability of population in buildings $V_{b(i) p(j)}$ $(s, t)$ depends on population density: a larger population density corresponds with a larger population vulnerability to landslides. Vulnerability of population, however, is not constant in time, but varies during the course of the day. We considered three different categories of buildings, namely residential, schools, and offices to quantify the population vulnerability at different times. It was found that $V_{b(i) p(j)}(s, t)$ in residential buildings is highest at night and morning time particularly between 2000 hours to 0800 hours. During those hours the vulnerability was generally constant because of low spatial variation in the population movement. $V_{b(i) p(j)}(s, t)$ values fluctuated rapidly between 0600 hours and 1000 hours and between
1600 hours and 1800 hours whereas $V_{b(i) p(j)}(s, t)$ in residential buildings between 1000 hours to 1600 hours is generally constant and low. For schools and office buildings $V_{b(i) p(j)}(s, t)$ values were low between evening 1700 hours to morning 0900 hours, because of low presence of persons in that period in these places. However, $V_{b(i) p(j)}(s, t)$ was high due to high density of population in these locations between 0900 hours and 1700 hours. To quantify $V_{b(i) p(j)}(s, t)$ for different buildings in the grid cells ten vulnerability maps were generated for different time intervals (Fig. 7).

\section{Vulnerability assessment of vehicles on road}

Figure 8 showed that the numbers of vehicles on a road section had a large variation at different time intervals of the day. The largest movement of vehicles on road sections was between 0800 hours and 1000 hours and between 1600 and 1800 hours. During the remainder of the day the traffic density was relatively constant; on an average two vehicles were expected to be present on the road during any given time interval. Night time traffic is not allowed in the study area during 2000 hours to 0600 hours and hence $V_{v(k)}(s, t)$ is expected to be zero during the night. Figure 8 also showed that under general traffic conditions the highest expected vehicle loss will not exceed four vehicles in any road section. Thus to assess $V_{v(k)}(s, t)$ on part of road section, a maximum of four (4) vehicles was considered as the upper threshold.

The Poisson distribution equation (8) was applied to calculate the vehicle vulnerability on different road section at different time of the day. Results show that $V_{v(k)}(s, t)$ varies throughout the day and that it depends on the number of vehicle present at any moment of time on a given section of road (Fig. 9). It was observed that in the study region the vulnerability of vehicle is above 0.6 in $50 \%$ of the road stretches between 0800 hours and 1000 hours and around $40 \%$ of the road stretch between 1600 to 1800 hours due to high traffic density on the road section. It was also noticed that the $V_{v(k)}(s, t)$ values are relatively lower during 1000 hours and 1600 hours, and 1800 hours and 2000 hours when the traffic density is moderate. $V_{v(k)}(s, t)$ is comparatively low between 0600 hours and 0800 hours. 

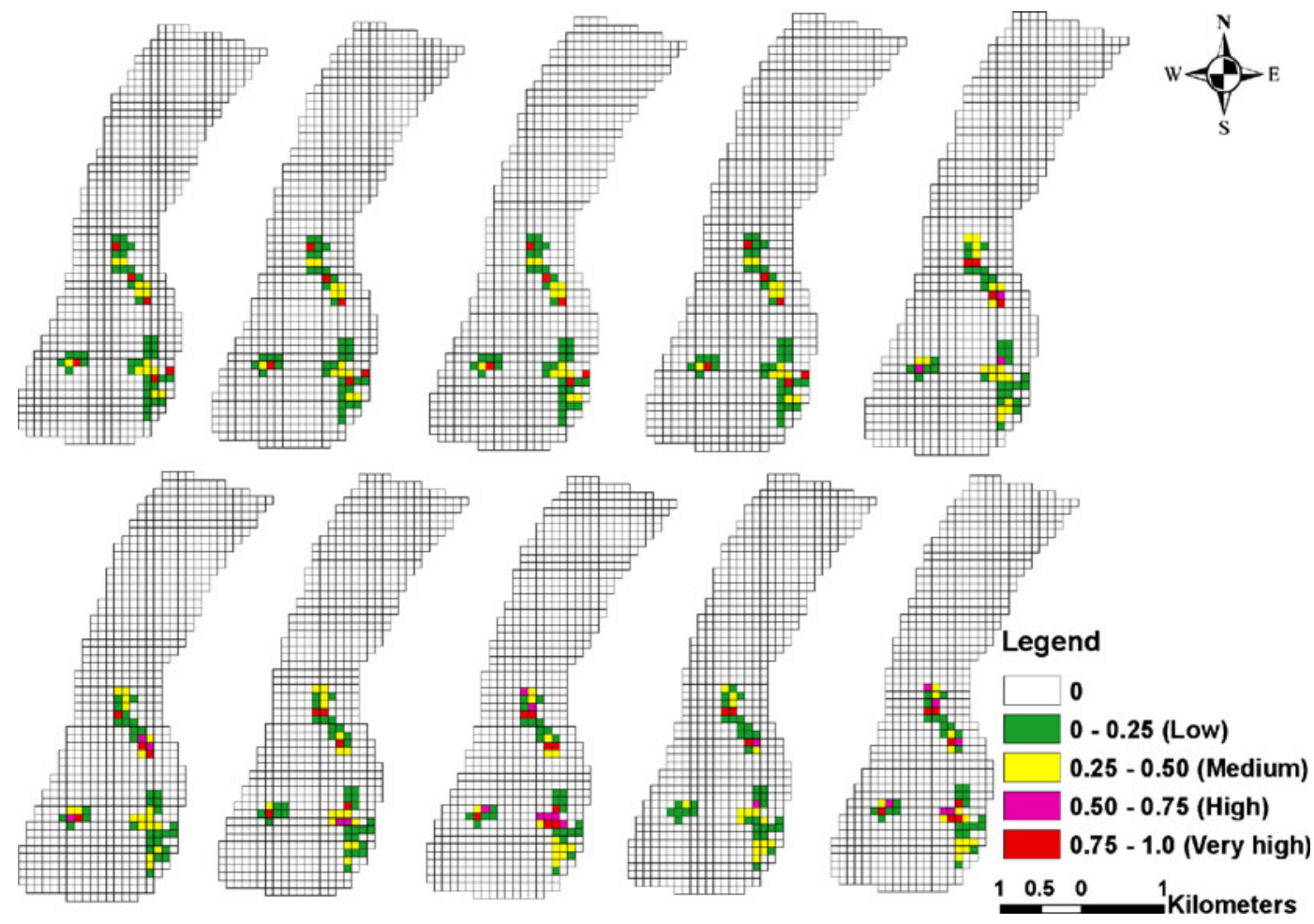

Fig. 7 Population vulnerability at different locations at different time zones of the day (clockwise from top left) (1) 0600-0800, (2) 0800-0900, (3) 0900-1000, (4) 1000-1200,
(5) 1200-1400, (6) 1400-1600, (7) 1600-1700, (8) 17001800, (9) 1800-2000, (10) 2000-0600 hours

and random through time; second, the complexities of landslide controlling factors coupled with dynamics of elements at risk make predictions uncertain in space and time. This leads to predictions that greatly depend on the way data are analyzed and the methods followed. So far there have only been a few attempts at quantifying the vulnerability to landslides (Galli and Guzzetti
Fig. 8 The expected number of vehicles at any given time zone for each of the seven road sections as derived using Eq. 7

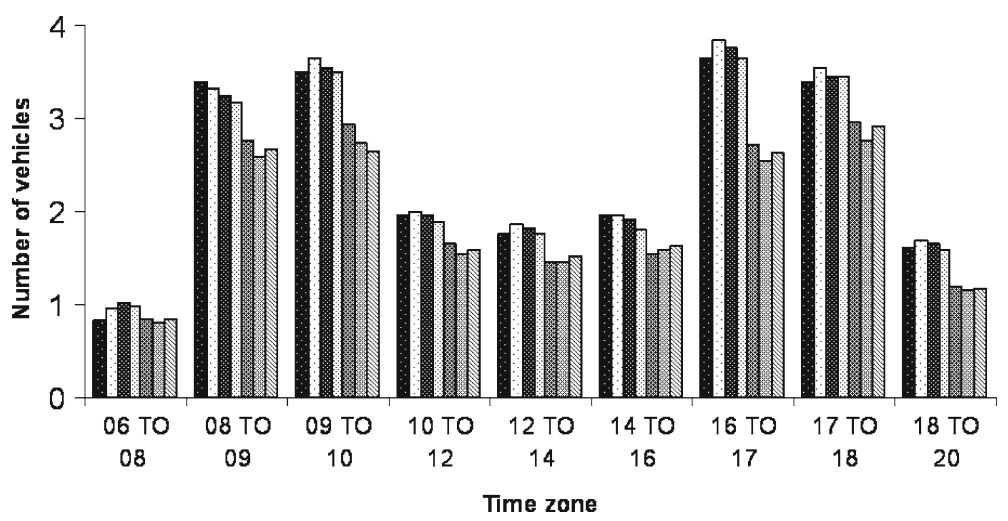


Fig. 9 Vulnerability of vehicles on different road sections at different time zones of the day (left to right) (1) 0600-0800,

(2) 0800-0900, (3) 09001000 , (4) 1000-1200,

(5) 1200-1400, (6) 14001600, (7) 1600-1700,

(8) 1700-1800, (9) 1800-

2000, (10) 2000-0600 hours

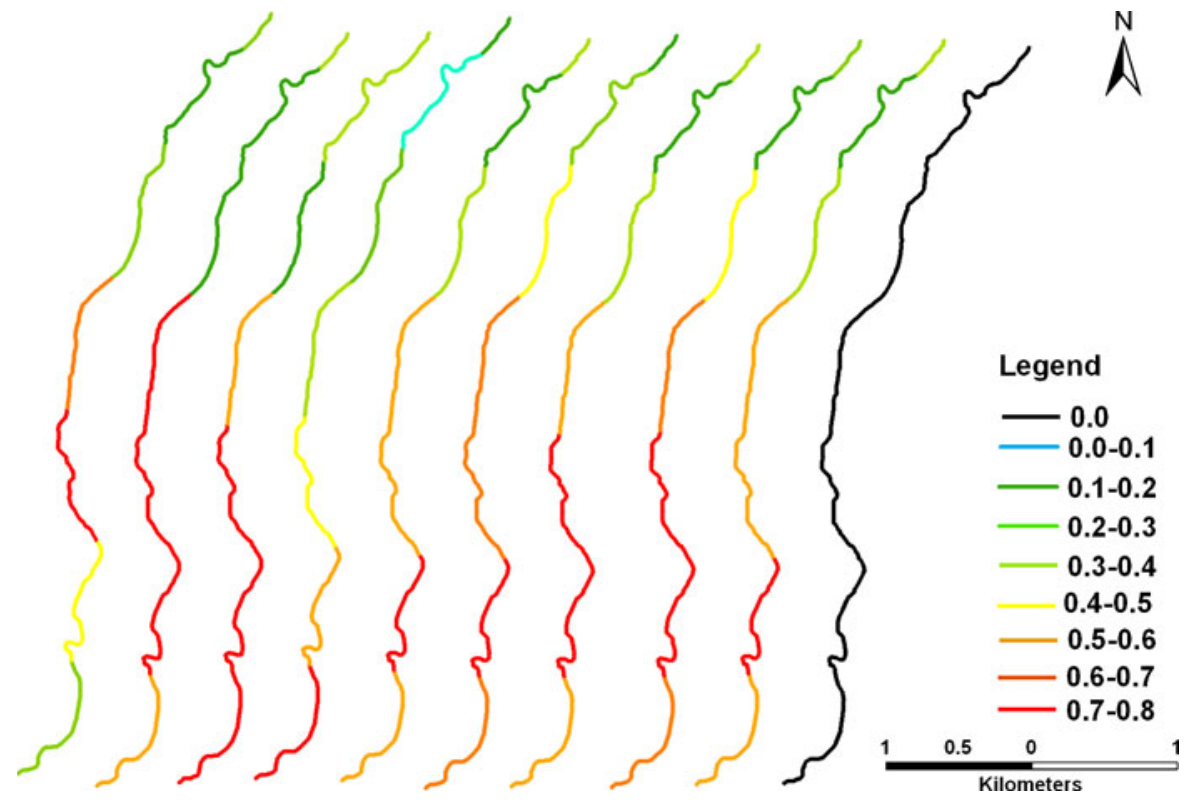

2007; Remondo et al. 2008; Kaynia et al. 2008). Most of the risk assessment studies for landslides do not focus on quantitative vulnerability assessment.

This study deals with a stochastic approach to assess the vulnerability to landslide hazard. The study presents a spatio-temporal framework for addressing the vulnerability of dynamic elements like population inside buildings and vehicles on road due to landslides. Not all the elements at risk change in similar way, some of these elements change slowly, e.g., in months or years, whereas other elements change more frequently, e.g., in minutes, hours, or days. Therefore vulnerability is high when the frequency or the density is high. Frequent changes occur for population in buildings and vehicles on a road. Hence, time of occurrence of the events also play a significant role in vulnerability assessment. An extensive field observation was carried out to monitor the pattern of changes. Land cover is also one of the dynamic elements in hilly terrain that changes seasonally or annually. Such changes can be extracted from the temporal satellite images and their vulnerability to landslide can be assessed using temporal landslide events.

The obtained results indicate that the vulnerability of elements at risk to landslide varies greatly in space and time. This variation was mainly due to the dynamic nature of the elements at risk. An assumption in this study is that the pattern of diurnal changes in the elements at risk is similar throughout the year. In subsequent studies, these assumptions may be relaxed and variation due to environmental causes such as change of rainfall patterns and social causes may be included. The age of people is also an important factor for determining the vulnerability. For simplification, this study does not make differentiation of people according to their age. However, as compared to old people, young people have a better response time and may escape the hazard quicker. The recovery time is also longer for the older people making their vulnerability higher than the young people.

It is difficult to validate the vulnerability results. Long time observations can be helpful in this case. Uncertain aspects of vulnerability in the absence of proper validation methods can be a major drawback for further increasing the scientific work. A large set of real-time data (movements of elements at risk), however, help to define the uncertainty in better manner. The stochastic approach we propose in this study is a reflection of statistical data analysis and manipulation, thus reducing the uncertainty. 
Vulnerability of any element in an area is proportional to the size of the property and population density in that area. A higher population density and property accumulation results in higher vulnerability. In the present study, we used field knowledge and information extracted from satellite images and analyzed population accumulation at different times of the day at different locations, vehicle frequency on a part of a road track at different times of the day. The present study identifies issues related to a quantitative vulnerability assessment to landslide hazards. It shows that the vulnerability of dynamic elements at risk can be assessed by means of a stochastic approach. As landslide events are uncertain in nature our study may help to improve vulnerability quantification of dynamic elements based on probability approach. Therefore, spatio-temporal analysis of the element at risk in stochastic framework can quantify the vulnerability that leads to a comprehensive landslide risk assessment.

\section{Conclusion}

The stochastic vulnerability assessment framework considered in this study includes elements like (1) buildings, (2) population inside the buildings in various time zones, and (3) the vehicles on the defined road stretch. A logistic regression model is applied for quantifying vulnerability of static element like buildings where as a Poisson model is adopted for the vulnerability assessment of dynamic elements like population and vehicles. The vulnerability in terms of probability values were obtained for each of these elements separately.

The study was undertaken over a landslide prone road corridor of Himalayas in India to demonstrate the spatio-temporal modeling of landslide vulnerability. We conclude that spatial and temporal probability associated with the various elements at risk can be analyzed in a stochastic framework for vulnerability assessment. This leads to different vulnerability values ranging between 0 and 1 for similar elements at risk at different times and places. Therefore, the stochastic vulnerability modeling can form a ba- sis for quantitative landslide risk analysis and assessment.

Acknowledgements This paper is the outcome of the research carried out under the framework of IIRSITC joint research project. The support by the Director, NRSC is highly acknowledged. We also thank Prof. R.C. Lakhera, Head, Geosciences Division, Dr. P.K. Champatiray, and Dr. Sameer Saran, Scientist, IIRS (NRSC), ISRO, Dehradun for their support and help.

Open Access This article is distributed under the terms of the Creative Commons Attribution Noncommercial License which permits any noncommercial use, distribution, and reproduction in any medium, provided the original author(s) and source are credited.

\section{References}

Agarwal, N. C., \& Kumar, G. (1973). Geology of the upper Bhagirathi and Yamuna valleys, Uttarkashi district, Kumaun Himalaya. Himalayan Geology, 3, 2-23.

Birkmann, J. (2007). Risk and vulnerability indicators at different scales: Applicability, usefulness and policy implications. Environmental Hazards, 7, 20-31.

Choubey, V. M., \& Ramola, R. C. (1997). Correlation between geology and radon levels in groundwater, soil and indoor air in Bhilangana valley, Garhwal Himalaya, India. Environmental Geology, 32, 258-262.

Dai, F. C., Lee, C. F., Ngai, Y. Y. (2002). Landslide risk assessment and management: An overview. Engineering Geology, 64(1), 65-87.

Das, I., Sahoo, S., Van Westen, C. J., Stein, A., Hack, R. (2010). Landslide susceptibility assessment using logistic regression and its comparision with a rock mass classification system, along a road section in the northern Himalayas (India). Geomorphology, 114, $627-637$.

Das, I., Srivastav, N., Lakhera, R. C. (2008). Rainfall threshold for landslide initiation: A probability based approach using historical landslides and rainfall records. Paper presented at the Indian Society of Remote Sensing Annual Symposium, 18-20 December, 2008, Ahmedabad, India.

Duzgun, H. S. B., \& Lacasse, S. (2005). Vulnerability and acceptable risk in integrated risk assessment framework. In F. Edited by Hunger, Couture and Emberhardt. (Ed.), Landslide risk management (pp. 505515). London: Taylor and Francis group.

Ebert, A., Kerle, N., Stein, A. (2009). Urban social vulnerability assessment with physical proxies and spatial metrics derived from air- and space borne imaging and gis data. Natural Hazards, 48(2), 275-294.

Elbers, C., \& Gunning, J. W. (2003). Vulnerability in stochastic dynamic model. Paper presented at the Discussion paper Tinbergen Institute, Amsterdam. TI2003-070/2. 
EM-DAT. (2008). List of landslide in india. Excel sheet. www.Em-dat.Net. Accessed on: 2008-09-11.

Fuchs, S. H. K., \& Hubl, J. (2007). Towards an empirical vulnerability function for use in debris flow risk assessment. Natural Hazards, 7, 495-506.

Galli, M., \& Guzzetti, F. (2007). Landslide vulnerability criteria: A case study from Umbria, central Italy. Environmental Management, 40, 649-664.

Glade, T. (2003). Vulnerability assessment in landslide risk analysis. Beitrag zur erdsystemforschung, 134(2), 123-146.

Guzzetti, F. (2005). Landslide hazard and risk assessment. Gemany: University of Bonn.

Hosmer, D., \& Lemeshow, S. (2000). Applied logistic regression (2nd edn. ed., Wiley series in probability and statistics). New York: Wiley.

Kaynia, A. M., Papathoma-Kohle, M., Neuhauser, B., Ratzinger, K., Wenzel, H., Medina-Cetina, Z. (2008). Probabilistic assessment of vulnerability to landslide: Application to the village of Lichtenstein, BadenWürttemberg, Germany. Engineering Geology, 101, 33-48.

Kohle, M. P., Neuhauser, B., Ratzinger, K., Wenzel, H., Howes, D. (2007). Element at risk as a framework for assessing the vulnerability of communities to landslides. Natural Hazards, 7, 765-779.

Liu, X. (2006). Site-specific vulnerability assessment for debris flows: Two case studies. Journal of Mountain Science, 3, 20-27.

Liu, X., \& Lei, J. (2003). A method for assessing regional debris flow risk: An application in zhaotong of yunnan province (SW China). Geomorphology, 52, 181-191.

Liu, X., Yue, Z. Q., Tham, L. G., Lee, C. F. (2002). Empirical assessment of debries flow risk on a regional scale in Yunnan province, southwestern China. Environmental Management, 30, 249-264.

Naithani, A. K., Kumar, D., Prasad, C. (2002). The catastrophic landslide of 16 July 2001 in Phata Byung area, Rudraprayag district, Garhwal Himalayas. Current Science, 82(8), 122-130.

NRSA. (2001). Atlas:Landslide hazard zonation mapping in the Himalayas of Uttarakhand and Himachal
Pradesh states using remote sensing and GIS. India: National Remote Sensing Agency, Hyderabad.

Papoulis, A. (1991). Probablity, random varibles, and stochastic processes, (p. 666). Boston: McGraw Hill.

Remondo, J., Bonachea, J., Cendrero, A. (2008). Quantitative landslide risk assessment and mapping on the basis of recent occurrences. Geomorphology, 94, 496-507.

Roberds, W. (2005). Estimating temporal and spatial variability and vulnerability (Landsldie risk management). London: Taylor and Francis group.

Saha, A. K., Gupta, R. P., Sarkar, I., Arora, M. K., Csaplovics, E. (2005). An approach for GIS-based statistical landslide susceptibility zonation-With a case study in the Himalayas. Landslides, 2, 61-69.

Shamaoma, H. (2005). Extraction of flood risk-related base-data from multi-source remote sensing imagery. Enschede: International Institute for Geo-information science and Earth observation (ITC), pp. 92.

United Nations, D. o. H. A. (1992). Internationally agreed glossary of basic terms related to disaster management, DNA/93/36, (pp. 1-6). Geneva.

Van Westen, C. J., Van Asch, T. W. J., Soeters, R. (2006). Landslide hazard and risk zonation-Why is it still so difficult? Bulletin Engineering Geology and Environment, 65, 167-184.

van Westen, C. J., Castellanos, E., Kuriakose, S. L. (2008). Spatial data for landslide susceptibility, hazard and vulnerability assessment: An overview. Engineering Geology, 102, 112-131.

Varnes, D. J. (1984). Landslide hazard zonation: A review of principles and practice. Review report. Paris: UNESCO.

Vinod Kumar, K., Bhattacharya, A., Martha, T. R., Bhaskar, P. V. (2003). Could Phata Byung, Uttarakhand landslide be prevented? Current Science, 85(6), 72-79.

Vinod Kumar, K., Lakhera, R. C., Martha, T. R., Chatterjee, R. S., Bhattacharya, A. (2008). Analysis of the 2003 Varunawat landslide, Uttarkashi, India using earth observation data. Environmental Geology, 55, 789-799. 